\title{
Implementação de novas práticas pedagógicas no Ensino Superior
}

\author{
Ana Ramos, Fernanda Delgado, Paulo Afonso, Alexandra \\ Cruchinho, Paula Pereira, Paula Sapeta \& George \\ Ramos \\ Instituto Politécnico de Castelo Branco, Portugal
}

\begin{abstract}
Resumo
A implementação de paradigmas no Ensino Superior resultantes da introdução do Processo de Bolonha abre portas para a renovação. A qualidade passa pela revisão dos curricula, pela reorganização dos processos de ensino-aprendizagem, pela estruturação das unidades curriculares e cursos, pela qualificação e formação de docentes, pelo sucesso e resultados escolares, pela avaliação das competências atingidas e pela confiança social no Ensino Superior. Em 2010, foi delineado o Projeto "Construção da Aprendizagem" (ConstAp) com o objetivo principal de motivar as mudanças, nomeadamente ao nível das metodologias adotadas e da implementação do trabalho autónomo, para garantir uma carga de trabalho do estudante contínua ao longo do semestre. A questão central é a melhoria da qualidade no ensino ministrado. Este artigo analisa a execução do projeto implementado no IPCB, desde o ano letivo 2009/10, no âmbito do Processo de Bolonha, contextualizando os seus objetivos, implementação e condicionantes.
\end{abstract}

Palavras-chave

ConstAp; ECTS; Ensino-aprendizagem; Trabalho autónomo

\section{Introdução}

A implementação do Processo de Bolonha, em Portugal, foi concretizada através da definição da estrutura dos ciclos de estudo e do novo 
modelo a adotar para o seu funcionamento. Esta alteração foi realizada, essencialmente, através da alteração legislativa imposta a todas as Instituições de Ensino Superior (IES), com prazos definidos para a entrada em vigor destas mudanças e para a concretização destas transformações. Desde 2006, quando este processo teve início, tem sido necessária uma adaptação contínua de todos os intervenientes no processo, tanto pelas alterações ao nível funcional como organizacional, o que promoveu o atraso nas alterações centrais: as mudanças pedagógicas.

De uma forma muito sintética, podemos dizer que o Processo de Bolonha se baseia num modelo de ensino centrado no estudante (European Comission, 2009) onde o foco é 'o que o estudante realiza' e 'como o relaciona com a atividade de aprendizagem'. Assim surge o sistema de créditos ECTS (European Credit Transfer and Accumulation System) e a quantidade de mudanças a ele associadas, implicando regimes de avaliação e de garantia da qualidade mutuamente reconhecidos. Neste contexto, é fundamental definir os níveis de conhecimento pretendidos, como o estudante os concretiza e se as competências necessárias foram atingidas em cada um deste níveis. Motivar o estudante para a aprendizagem e para a participação nas atividades propostas pressupõe ainda dar significado a estas atividades, despertando o interesse em desenvolvê-las (Biggs \& Tang, 2007). Esta tarefa está diretamente relacionada com o docente ou formador, vulgo professor neste nível de ensino.

Ser professor do Ensino Superior é, ainda, certamente, considerado pela sociedade em geral como sendo um privilégio a que apenas algumas pessoas, poucas, têm acesso. Esta visão sobre o estatuto social que o docente deste nível de ensino possui transporta consigo uma carga de exigência intelectual e social (Cachapuz, 2001) que sempre acompanhou esta profissão ao longo dos tempos. Situados ao nível do topo do conhecimento científico afeto à sua área de intervenção profissional, os docentes do Ensino Superior desde sempre foram alvo de admiração por parte da maioria dos seus aprendentes e familiares mais próximos. Importantes agentes de aprendizagem, os docentes deste nível de ensino eram considerados, até há bem pouco tempo, o mais importante, senão o único, meio de (in)formação dos estudantes. Detentores de um saber ímpar, marcavam um papel preponderante ao nível da relação, tendencialmente unidirecional, professorestudante. 
Contudo, o tempo de hoje é outro, pois, para além do professor do Ensino Superior dever continuar a preocupar-se com o domínio científico dos conteúdos a trabalhar com os seus estudantes, também deve passar a dar atenção ao que se passa ao nível do ambiente de aprendizagem relativo às unidades curriculares que ministra. Concordamos com Guerra (1990, cit. em García-Valcárcel, 2001, pp. 9-10), quando refere que:

el profesor ha de ser un conocedor de la disciplina que desarrolla, un especialista en el campo del saber, permanentemente abierto a la investigación y a la actualización del conocimiento. Pero ha de saber, también, qué es lo que sucede en el aula, cómo aprenden los alumnos, cómo se puede organizar para ello el espacio y el tiempo, qué estrategias de intervención pueden ser más oportunas en ese determinado contexto.

De facto, recentemente, a componente pedagógica afeta à docência do Ensino Superior tem merecido a atenção dos especialistas em Ciências da Educação. A título de exemplo, Cachapuz (2001) refere a necessidade de haver "um aperfeiçoamento pedagógico dos docentes" (p. 56). Esta sugestão vem ao encontro da ideia defendida por Román (1980) no sentido de se contrariar a tendência excessiva para o verbalismo, dogmatismo e a tipologia de classe magistral deste tipo de ensino. Hoje valoriza-se, pois, "a interacção e a troca de informação entre professor e aluno. No lugar da reprodução passiva de informações já existentes, deseja-se cada vez mais o estímulo à criatividade dos estudantes" (Blikstrein \& Zuffo, 2003, p. 25). A inter-relação entre a investigação, a inovação e a necessidade de formação é uma necessidade profissional que os professores deverão construir, com benefícios para o aprendente (Gonçalves, 2006).

No sentido de se adaptarem às alterações paradigmáticas do ato de ensinar-aprender, propostas pelo Processo de Bolonha, muitas IES investiram em metodologias de ensino não presencial, não só para diversificarem o leque de oferta formativa, mas também para incutirem no estudante o papel de agente ativo da sua própria aprendizagem. Termos como e-learning, $b$ learning, formação síncrona e assíncrona, competências, carga de trabalho, passaram a fazer parte do vocabulário inerente aos ambientes de ensinoaprendizagem propostos pelas instituições deste nível de ensino. Contudo, atente-se à chamada de atenção produzida por Ardizzone \& Rivoltella (2004) ao referirem-se ao termo "falácia tecnológica" (p. 29), pois não basta 'transportar' os cursos, tal qual eles existem, para as plataformas de ensino à 
distância para que se possam produzir milagres de aprendizagem nos estudantes. De facto, concordamos igualmente com Lagarto \& Andrade (2009) ao referirem que:

A Sociedade da Informação e a Internet trouxeram ao mundo da educação e da formação novos paradigmas para ensinar e aprender. Se através da Internet podem ser disponibilizados conteúdos de uma forma mais alargada, mais rápida, atractiva e interactiva que antes, a verdade é que isso pode implicar a necessidade de novos modelos de ensino e aprendizagem bem como da sua distribuição (p. 56).

Não basta, pois, haver evolução tecnológica para que se possa pensar que os resultados de aprendizagem melhoram de forma tácita. De acordo com Bustamante (2001), ter-se-ão que conceber conteúdos de qualidade, adaptados a cada realidade local, concebidos não apenas pelos docentes, mas tendo também o auxílio de especialistas em comunicação à distância. Utilizar plataformas tecnológicas de ensino-aprendizagem, que permitem uma enorme interatividade dos agentes que a ela se ligam, para promover materiais didáticos estáticos como são os tutoriais, sebentas ou algumas sugestões de leitura para que os estudantes possam aprender, é desaproveitar as potencialidades interativas dessas plataformas formativas (Belisário, 2003).

Sensibilizar os docentes e os estudantes para a necessidade de estes últimos promoverem competências de estudo autónomo eficaz que lhes permitam ter sucesso no Ensino Superior, à luz do Processo de Bolonha, é uma das principais finalidades inerentes à conceção do Projeto ConstAp, que o Instituto Politécnico de Castelo Branco (IPCB) quer ver incutido em todos os seus cursos. Para tal, interessará saber em que medida as plataformas de ensino-aprendizagem à distância poderão contribuir para que o estudo autónomo dos alunos seja eficaz, bem como saber que tipo de tarefas são propostas para o desenvolvimento da componente do estudo autónomo, e analisar a forma como são monitorizadas essas atividades pelos docentes.

A melhoria das práticas de ensino é, para os bons professores, um estímulo evolutivo e de partilha, mas este processo é mais eficaz se se traduzir num processo académico, fundamentando-se estas mudanças em dados, e não suposições, pelo que são necessários modos de recolha de informação e de documentação para partilha de novas práticas pedagógicas. 
Dada a natureza do processo de ensino-aprendizagem, a sua complexidade e a sua multidimensionalidade, para ser avaliado é necessário fazê-lo a partir de várias fontes. Desde logo, existe a necessidade de considerar os atores do processo, docentes e estudantes, assim como os outros agentes envolvidos, tais como os órgãos de gestão científica e pedagógica da IES.

Aos docentes e estudantes, a aplicação de questionários, onde possam ser inquiridos diretamente sobre a maioria dos indicadores/critérios considerados, passa por ser uma fonte de informação relevante. Os resultados de inquéritos de avaliação de desempenho pedagógico de docentes e da avaliação da unidade curricular pelo docente constituem outro elemento fundamental em termos quantitativos. A validação das metodologias pelo órgão científico da IES constitui uma garantia relativamente à adequação entre as várias componentes, os conteúdos programáticos, os objetivos e as competências pretendidas para cada ciclo de estudos.

O Ensino Superior é uma teia complexa de competências, conhecimentos e aptidões. Nenhuma preparação, por muito boa que seja, dura toda uma carreira. Os estudantes e as suas atitudes para a aprendizagem mudam com o passar do tempo, assim como a investigação sobre o ensino evolui.

\section{O paradigma da mudança}

De acordo com Tyler, "Learning takes place through the active behavior of the student: it is what he does that he learns, not what the teacher does" (cit. em Biggs \& Tang, 2007, s/p).

A utilização de métodos expositivos, essencialmente baseados na ação do docente, é uma característica do modelo tradicional de ensino. Neste novo contexto, importa refletir sobre estas práticas e tentar orientar a atividade pedagógica para a adoção de técnicas e atividades que fomentem a participação do estudante (Esteves, 2010; Leite \& Ramos, 2010; Ramos, Costa, Tavares, \& Huet, 2006). A aprendizagem deve estar centrada no que o estudante é capaz de fazer, motivando o trabalho individual e cooperativo no sentido de desenvolver competências transversais (soft skills) fundamentais, como a capacidade de trabalho em equipa. 
Na transição para a adoção dos princípios inerentes ao Processo de Bolonha, se a questão da alteração dos graus beneficiou de uma maior visibilidade pública, o acolhimento do sistema de créditos (ECTS) teve um impacto mais significativo na organização pedagógica das IES. Enquanto o anterior sistema de créditos se baseava no número de horas de ensino presencial, as novas unidades de crédito são baseadas no número de horas despendidas pelo estudante no seu processo de aprendizagem. Este novo sistema requer, por um lado, uma definição clara dos objetivos da formação em termos de competências a adquirir e uma grande flexibilidade curricular, e, por outro, centralizar o estudante no processo de aprendizagem.

Esta centralização corresponde a uma prática de ensino que se entende invertida relativamente a modelos mais tradicionais: em vez de se passar conhecimento prêt-a-porter, sustentado por um manancial bibliográfico de larga escala, incentiva-se o estudante a procurar esse conhecimento por meios próprios, permitindo empowerment e autonomia ao aprendente, relevando as componentes de trabalho experimental e as competências transversais, favorecendo o desenvolvimento da sua criatividade e cimentando o raciocínio crítico (Vieira, Mamede, \& Lima, 2008).

$O$ ensino centrado no estudante (ECE) constitui um quadro mental e cultural, correspondendo a uma abordagem relacionada com as investigações das teorias construtivistas de aprendizagem. É caracterizado por métodos inovadores de ensino que procuram a aprendizagem em interação com os professores e outros estudantes, capacitando os estudantes para uma aprendizagem ativa através da resolução de problemas, raciocínio crítico e reflexivo (Attard, Di lorio, Geven, \& Santa, 2010). Os princípios mais sustentados relativamente ao ECE correspondem, de acordo com Attard et al. (2010), Santa \& Geven (2010) e Biggs \& Tang (2007), aos seguintes aspetos: i) um processo reflexivo contínuo; ii) não existem receitas de sucesso garantido; iii) os estudantes possuem estilos de aprendizagem diferentes; iv) os estudantes detêm interesses e necessidades distintas; v) a possibilidade de escolha é central a uma aprendizagem efetiva; vi) os estudantes têm experiências e conhecimento de base diferentes; vii) os estudantes devem poder controlar a sua aprendizagem; viii) focalização na permissão para explorar o conhecimento e não na sua transmissão; ix) atitudes cooperativas entre estudantes e professores. 
O ECE corresponde a um modelo alternativo que se focaliza no que é expectável que os estudantes consigam fazer no final do módulo ou unidade - é, neste sentido, uma abordagem baseada nos resultados da aprendizagem (Kennedy, Hyland, \& Ryan, 2007).

A correspondência entre os resultados de aprendizagem (learning outcomes), as metodologias de ensino-aprendizagem e o processo de avaliação tem sido alvo de estudo por diferentes investigadores, nomeadamente Houghton (2004) e Biggs \& Tang (2007), que invocam o conceito de 'alinhamento construtivo' (constructive alignment), considerandoo um dos conceitos mais estimulantes aplicados ao Ensino Superior. O pressuposto de todo o sistema é de que o currículo é criado para que as atividades de aprendizagem e as tarefas de avaliação sejam coerentes com os objetivos de aprendizagem que se pretendem atingir numa determinada unidade curricular.

Neste sentido, "Learning outcomes are statements of what a learner is expected to know, understand and/or be able to demonstrate after completion of a process of learning" (Kennedy et al., 2007, p. 5), deslocando-se o núcleo central da formação do ensino para a aprendizagem. Esta revalorização da educação, que recorre ao debate e à reflexão (por oposição a uma cultura formativa de reprodução do saber e do consumo das ideias de terceiros), é credora da coerência referida anteriormente e permitirá ao estudante, numa sociedade baseada no domínio do conhecimento, uma permanente capacidade de lidar com mudança e readaptação (Zabalza, 2003).

As dificuldades dos diferentes países em alterar os sistemas tradicionais de ensino e aprendizagem (seja centralizando o ensino no estudante, seja baseando esse ensino em competências) têm sido difíceis de ultrapassar, a nível nacional, mas principalmente a nível supranacional: "(...) under the surface of the same Bachelor-Master structure the sea is full of different and incomparable fish" (Ritzen, 2010, p. 175).

Tendo por base os princípios do constructive alignment, que descreve a congruência entre o que o professor entende que os estudantes devem ser capazes de executar, saber ou entender, 'como deve ser ensinado', 'o que' e 'como' deve ser avaliado (Fry, Ketteridge, \& Marshall, 2009), foi delineado um projeto denominado "Construção da Aprendizagem" (ConstAp) no IPCB. 
$122 \mid$ Ana Ramos et al.

\section{O Projeto ConstAp}

O Projeto ConstAp foi gizado considerando-se como objetivos maiores: os desafios do Processo de Bolonha; o ensino centrado no estudante; um ensino baseado na aquisição de competências. Um objetivo, também fundamental, intrínseco ao modelo relaciona-se com os aspetos de qualidade do ensino e a resposta a dar pelos cursos relativamente a procedimentos de avaliação de ciclos de estudo no âmbito da Agência de Acreditação. Para tentar responder às exigências deste processo, a Coordenação Institucional do Processo de Bolonha (Grupo nomeado no IPCB para promover a adoção dos princípios constantes da Declaração de Bolonha na IES) apresentou a proposta de um projeto que permitisse responder a algumas lacunas evidenciadas pelo Relatório de Concretização do Processo de Bolonha no IPCB para o ano letivo 2009/10. Os desafios referidos anteriormente dependem maioritariamente da motivação e iniciativa dos docentes, pelo que o projeto permite promover uma discussão alargada sobre as mudanças necessárias no Ensino Superior.

A dinâmica de desenvolvimento do projeto enquadra-se no sentido de facilitar o acesso a um conjunto de ferramentas pedagógicas não generalizadas na instituição, procurando melhorar o ensino e a aprendizagem. Quanto aos objetivos específicos, podem-se apontar: motivar a utilização de métodos ativos de ensino-aprendizagem e a implementação de uma metodologia de avaliação contínua; ajustar a carga de trabalho do estudante ao longo de todo o semestre (com uma distribuição semanal); acompanhar o tempo dedicado ao trabalho autónomo, orientado pelo professor da UC; desenvolver um processo de autorregulação da aprendizagem por parte do estudante (método de trabalho); promover a cooperação e coordenação das várias atividades pedagógicas desenvolvidas ao longo do ano; possuir dados concretos sobre o percurso formativo para análise no âmbito da avaliação da qualidade dos cursos.

O projeto define alguns instrumentos de acompanhamento que revertem num processo metodológico de definição de atividades de aprendizagem, seus objetivos e competências a desenvolver. $O$ acompanhamento é realizado através de fichas específicas para as atividades desenvolvidas nas horas de contacto e nas horas destinadas ao trabalho autónomo do estudante. Estas fichas foram definidas considerando-se a 
disponibilização de informação aos estudantes de uma forma semelhante e a recolha da informação que permitisse aferir alguns aspetos do processo pedagógico, tais como:

- Tipologia das atividades desenvolvidas pelos docentes nas horas de contacto e dinâmica na sua utilização;

- Tipologia de atividades propostas para o trabalho autónomo dos estudantes;

- Valorização da atividade desenvolvida pelos estudantes em sala de aula através do seu contributo no processo de ensinoaprendizagem;

- Tempos de avaliação e organização do trabalho ao longo do ano letivo;

- Relação entre o tempo previsto pelo docente para a realização das atividades autónomas, definido no programa da unidade curricular, e tempo efetivamente utilizado pelo estudante para a realização das atividades;

- Organização e articulação do trabalho num curso (em todas as suas dimensões), considerando todas as unidades curriculares do plano em causa.

O projeto, desde o seu início, foi criado considerando a sua implementação no $1^{\circ}$ ano dos cursos, com o objetivo de contribuir para a integração dos estudantes neste contexto formativo no início do seu percurso no Ensino Superior, facilitando o seu sucesso no ano curricular e imprimindo dinâmicas de gestão de tempo e de organização pessoal que conduzissem ao seu sucesso também nos anos curriculares subsequentes, visando a diminuição do insucesso académico e do abandono escolar.

\section{Metodologia}

Em termos metodológicos, é proposto que o docente disponibilize, no início de cada semana, os planos das aulas a lecionar, identificando claramente as atividades que serão desenvolvidas, assim como a sua tipologia. Estas atividades devem estar diretamente relacionadas com as competências a adquirir, permitindo ao estudante relacionar os conteúdos 
com a prática pedagógica. As atividades de avaliação decorrem deste processo e devem resultar das suas etapas. Deve, por outro lado, existir uma definição clara das atividades a desenvolver durante o trabalho autónomo, que devem constituir elementos de complementaridade relativamente às horas de contacto, e realizar-se o controlo do tempo despendido pelo estudante para as executar.

Ponderando o objetivo de sistematizar o processo de ensinoaprendizagem, considerou-se a adoção de princípios de planificação e organização das atividades pedagógicas transversais, que permitam ao estudante uma perceção clara dos objetivos e competências envolvidos em cada etapa do seu percurso formativo. É ainda necessário promover a intensificação da utilização de um processo de avaliação contínua e relacionar os momentos de avaliação com as atividades de aprendizagem desenvolvidas.

O Projeto ConstAp pretende facilitar uma análise formal do tempo de trabalho dedicado pelo estudante ao estudo autónomo, realizado de forma consistente através da orientação fornecida pelo docente. A realização deste registo permite aferir a carga de trabalho dos estudantes num determinado ano/curso.

Finalmente, a implementação de uma Grelha Única de Avaliação permite, a todos os docentes envolvidos na lecionação, o acompanhamento do aproveitamento dos estudantes, identificando durante o percurso formativo os casos de insucesso ou abandono escolar. Este acompanhamento permite o conhecimento atempado de situações de insucesso ou abandono escolar, o que viabiliza uma intervenção no sentido de reverter o processo ao articularse com o sistema de acompanhamento do estudante delineado na instituição (Regime de Tutorias).

\section{Implementação do Projeto}

\subsection{Fase I}

O Projeto foi implementado em alguns cursos do IPCB, com a participação voluntária dos docentes, sendo os dados recolhidos analisados com base numa matriz criada para este efeito. Esta matriz contempla a análise da dinâmica durante as horas de contacto, assim como a tipologia 
adotada para o trabalho autónomo e a carga que este representa no trabalho semanal do estudante. Esta análise permite ainda aferir a gestão dos trabalhos propostos aos estudantes e o tempo de trabalho final face ao que inicialmente foi previsto (ECTS).

Em termos dos indicadores de avaliação, preconiza-se a obtenção de informação relativamente a: atividades realizadas; metodologias utilizadas nessas atividades; repartição dos momentos de avaliação ao longo do semestre/ano; relação entre as horas de estudo autónomo previstas (no plano curricular) e as que foi possível apurar; dificuldades verificadas.

As ações para a implementação do projeto foram desenvolvidas sequencialmente e podem-se resumir em: 1. sessão de esclarecimento em todas as escolas sobre as questões essenciais do projeto e a sua operacionalização; 2. acompanhamento e incentivo, ao longo do período lectivo, da implementação do projeto; 3. recolha de dados a partir das fichas coletadas de todas as unidades curriculares; 4 . análise estatística simples dos dados; 5. formulação de relatórios: global, com reporte à instituição; por curso, com reporte aos coordenadores de curso.

\subsection{Resultados}

Tendo em linha de conta os objetivos definidos, as questões a responder e os indicadores de avaliação preconizados, referidos anteriormente, foi possível extrair alguns resultados - já que o projeto se encontra a ser implementado no IPCB desde o ano letivo 2010-2011 -, que passamos a especificar.

1. A reunião de um conjunto de informação relativamente às atividades e metodologias utilizadas pelos docentes. Podem-se observar as tabelas exemplificativas (Tabelas 1, 2 e 3) relativas a algumas unidades curriculares de um curso ministrado no IPCB. 
Tabela 1 - Unidades Curriculares (UC) e carga de trabalho dos estudantes, segundo as diversas tipologias, de um

Curso ministrado no IPCB

\begin{tabular}{|c|c|c|c|}
\hline UC DO CURSO & ECTS & HORAS TOTAIS & $\begin{array}{l}\text { HORAS DE ESTUDO } \\
\text { AUTÓNOMO }\end{array}$ \\
\hline UCI & 5 & $\begin{array}{c}135 \text { horas } \\
\text { (TP: } 90 \mathrm{~h} ; \text { OT: } 5 \mathrm{~h} ; \mathrm{O}: 4 \mathrm{~h})\end{array}$ & 36 horas \\
\hline UC II & 5 & $\begin{array}{c}135 \text { horas } \\
\text { (TP: } 90 \mathrm{~h} ; \text { OT: } 5 \mathrm{~h} ; \mathrm{O}: 4 \mathrm{~h})\end{array}$ & 36 horas \\
\hline UC III & 6 & $\begin{array}{c}162 \text { horas } \\
\text { (TP: 60h; OT: } 6 \mathrm{~h} ; \mathrm{O}: 4 \mathrm{~h})\end{array}$ & 92 horas \\
\hline UC IV & 6 & $\begin{array}{c}162 \text { horas } \\
\text { (TP: 60h; OT: } 6 \mathrm{~h} ; \mathrm{O}: 4 \mathrm{~h})\end{array}$ & 92 horas \\
\hline UC V & 4 & $\begin{array}{c}108 \text { horas } \\
\text { (TP: } 60 \mathrm{~h} ; \text { OT: } 4 \mathrm{~h} ; \mathrm{O}: 4 \mathrm{~h})\end{array}$ & 40 horas \\
\hline UC VI & 4 & $\begin{array}{c}108 \text { horas } \\
\text { (TP: 60h; OT: } 4 \mathrm{~h} ; \mathrm{O}: 4 \mathrm{~h} \text { ) }\end{array}$ & 40 horas \\
\hline
\end{tabular}

Tabela 2 - Enumeração das atividades realizadas nas UC's

\begin{tabular}{ll}
\hline UC & ACTIVIDADES \\
\hline UC II & $\begin{array}{l}\text { Trabalhos práticos com apresentação oral, prova } \\
\text { escrita }\end{array}$ \\
UC III & Relatórios, trabalho prático e prova escrita \\
UC IV & Relatórios e construção de grelhas de avaliação de ... \\
UC V & $\begin{array}{l}\text { Relatório, trabalhos práticos, exposição } \\
\text { oral/audiovisual }\end{array}$ \\
\hline
\end{tabular}

Tabela 3 - Metodologias pedagógicas utilizadas nas diversas atividades e UC's

\begin{tabular}{ll}
\hline UC & METODOLOGIAS UTILIZADAS \\
\hline UCII & $\begin{array}{l}\text { Leitura de obra literária e respetiva apresentação, tradução de folheto } \\
\text { elaborado na UC '...', pesquisa, seleção e exposição de informação para } \\
\text { apresentar um ..., prova escrita }\end{array}$ \\
UCIII & $\begin{array}{l}\text { Exposição teórica, ensino pela descoberta, debate, trabalho prático com } \\
\text { apresentação oral/audiovisual, prova escrita }\end{array}$ \\
& $\begin{array}{l}\text { Visionamento de vídeo, resposta a questões, análise e discussão em } \\
\text { grupo, apresentação de conclusões, construção de grelhas de avaliação de } \\
\text { U.., percurso '...' e elaboração de relatório, visita de estudo '...' e } \\
\text { elaboração de relatório } \\
\text { Elaboração de relatório sobre uma temática, trabalho prático, exposição } \\
\text { oral/audiovisual }\end{array}$ \\
\hline
\end{tabular}


2. Regista-se uma repartição desigual das atividades, tanto em termos das diversas unidades curriculares no contexto de um curso, como entre os diversos cursos - coexistem unidades curriculares que repartem atividades ao longo do período de estudo com outras que concentram as atividades num conjunto limitado de momentos, e ainda com as que concentram num período específico as atividades relacionadas. Pode-se aferir esta ilação a partir da exemplificação relativa a algumas unidades curriculares (Tabela 4).

Tabela 4 - Momentos de entrega de Trabalhos Autónomos (TA) e/ou Prova Escrita (PE)

\begin{tabular}{|c|c|c|c|c|c|c|c|c|c|c|c|c|c|c|c|}
\hline \multirow{2}{*}{ UC } & \multicolumn{15}{|c|}{ Semanas } \\
\hline & & 1 & 2 & 3 & 4 & 5 & 6 & 7 & 8 & 9 & 10 & 11 & 12 & 13 & 14 \\
\hline \multirow{2}{*}{$\begin{array}{c}\text { UC } \\
\text { II }\end{array}$} & TA & & & & & & & & & TA1TA2 & TA3 & & & & \\
\hline & PE & & & & & & & & & & & \multicolumn{4}{|c|}{ PE1 } \\
\hline \multirow{2}{*}{$\begin{array}{l}\text { UC } \\
\text { III }\end{array}$} & TA & & & TA1 & TA2 & & TA3 & & & & TA4 & & & & TA5 \\
\hline & PE & & & & & & & & & & & \multicolumn{4}{|c|}{ PE1 } \\
\hline \multirow{2}{*}{$\begin{array}{l}\text { UC } \\
\text { IV }\end{array}$} & TA & & TA1 & & TA2 & $\begin{array}{l}\text { TA2 } \\
\text { TA3 }\end{array}$ & TA2 & $\begin{array}{l}\text { TA2 } \\
\text { TA4 }\end{array}$ & TA2 & TA2 & TA2 & TA2 & TA2 & TA2 & TA5 \\
\hline & PE & & & & & & & & & & & & & & \\
\hline \multirow{2}{*}{$\begin{array}{c}\text { UC } \\
v\end{array}$} & TA & & TA1 & & TA2 & $\begin{array}{l}\text { TA2 } \\
\text { TA3 }\end{array}$ & TA2 & $\begin{array}{l}\text { TA2 } \\
\text { TA4 }\end{array}$ & TA2 & TA2 & TA2 & TA2 & TA2 & TA2 & TA5 \\
\hline & PE & & & & & & & & & & & & & & \\
\hline
\end{tabular}

3. Aquela desigual repartição de atividades afeta o tempo de trabalho dedicado pelo estudante ao longo do período (semestre/ano). Esta repartição desigual pode ser observada nos Gráficos 1 e 2 .

\section{Gráfico 1 - N..$^{\circ}$ de atividades e tempo de estudo autónomo}

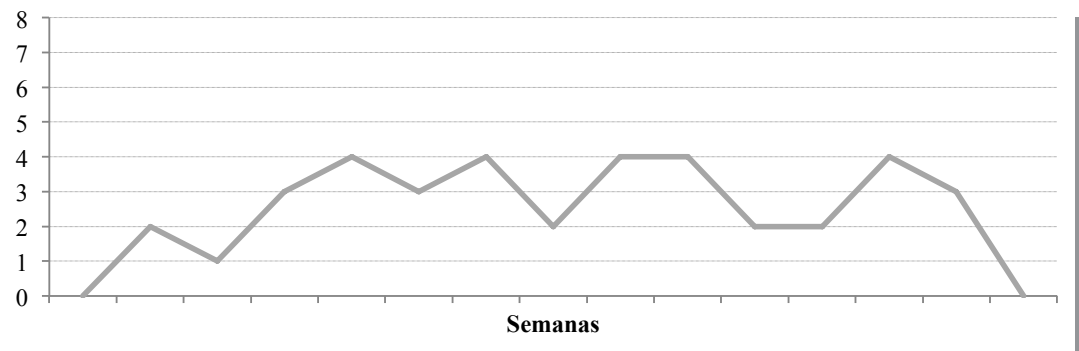


128 Ana Ramos et al.

\section{Gráfico 2 - Tempo médio despendido (horas)}

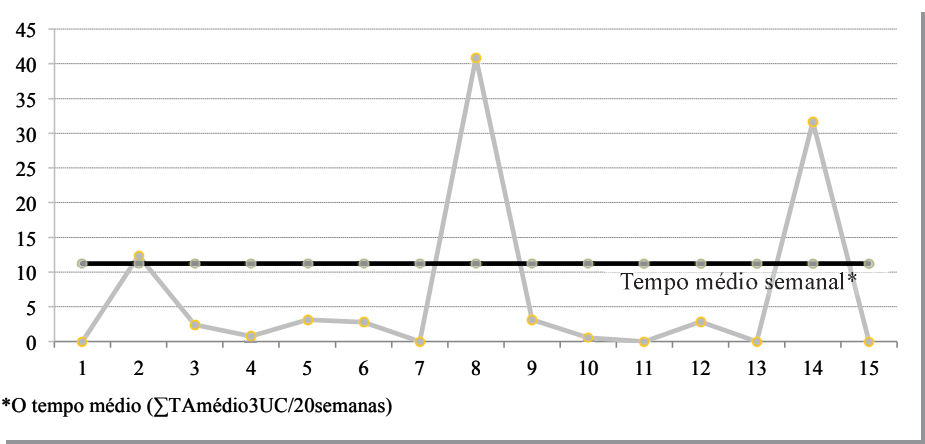

4. É possível afirmar, com um grau de certeza ainda não validado, que o tempo de trabalho desenvolvido pelos estudantes é inferior ao previsto na atribuição de ECTS (Tabela 5 e Gráfico 3), permitindo extrair a informação que ainda predomina um modelo de avaliação mais tradicional.

Tabela 5 - Relação Horas de Trabalho Autónomo previsto e realizado

\begin{tabular}{lccc}
\hline UC & $\begin{array}{c}\text { TA Previstas } \\
\mathbf{( 1 )}\end{array}$ & $\begin{array}{c}\text { TA Apuradas } \\
\mathbf{( 2 )}\end{array}$ & $\begin{array}{c}\text { Diferença } \\
\mathbf{( 3 )}=\mathbf{( 1 )}-\mathbf{( 2 )}\end{array}$ \\
\hline UC II & 36 horas & $\mathrm{SI}$ & --- \\
UC III & 92 horas & 34 horas & 58 horas \\
UC IV & 92 horas & 18 horas & 74 horas \\
UC V & 40 horas & 48 horas & -8 horas \\
\hline Nota: SI - Sem Informação & &
\end{tabular}




\section{Gráfico 3 - Relação Horas de Trabalho Autónomo previsto e realizado}

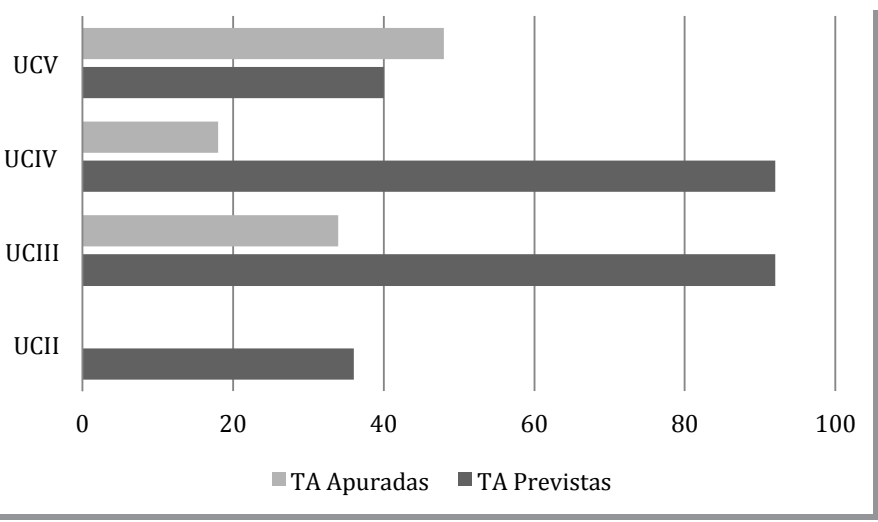

\section{Projeto ConstAp: O novo modelo - Fase II}

\subsection{Dificuldades e redefinição de elementos do Projeto}

Da implementação deste projeto, no $2^{\circ}$ semestre do ano letivo 2010/11, foi possível analisar não só os dados recolhidos, mas também as considerações e propostas dos professores envolvidos, no sentido de simplificar e agilizar as ferramentas de acompanhamento do projeto e de recolha de dados. De entre as principais dificuldades referidas pelos professores podemos salientar: i) a necessidade de preenchimento de um número excessivo de fichas; ii) a dificuldade em compreender alguns dos elementos solicitados; iii) a fiabilidade da informação dos estudantes em relação ao tempo de trabalho autónomo.

No âmbito da coordenação do projeto também é importante manifestar a dificuldade em consciencializar os professores sobre a necessidade de orientar o trabalho autónomo dos estudantes e monitorizar a sua execução, assim como prever ferramentas que permitam valorizá-los no âmbito da avaliação da unidade curricular. Embora o tempo de trabalho do estudante deva ser continuado ao longo do semestre, é possível identificar períodos com cargas de trabalho excessivas e outros sem qualquer atividade autónoma. Aprofundar os conhecimentos dos professores no âmbito da pedagogia é fundamental, porque o "acto pedagógico pode funcionar como elemento potenciador dos factores concorrentes para o (in)sucesso escolar" (Veloso, Costa, \& Lopes, 2010, p. 56). Foi igualmente possível identificar algumas 
carências ao nível da inovação pedagógica e da formação contínua dos docentes.

Após análise destes elementos, considerou-se necessário proceder a uma reformulação e simplificação das fichas utilizadas para recolha de informação no sentido de recolher os dados fundamentais ao acompanhamento da atividade pedagógica.

\subsection{Reformulação do Projeto - Fase II}

Atendendo à informação coletada, seja por via de observações de docentes, seja pela análise da operacionalização do projeto, podem referir-se algumas das reflexões que foram efetuadas pela equipa responsável no sentido de introduzir melhorias: explicitar melhor a componente operacional do projeto; reestruturar as fichas disponibilizadas, facilitando o seu preenchimento; incentivar a participação de mais unidades curriculares no projeto, nos cursos onde foi implementado anteriormente; alargar a sua implementação a outros cursos, nas diversas unidades orgânicas do IPCB; aprofundar o sistema de acompanhamento da implementação.

A revisão da forma de implementação do projeto e subsequente alteração das fichas disponibilizadas ao docente, que deverão ser de resposta mais fechada, foi uma medida imperiosa resultante da experiência do $1^{\circ}$ ano de implementação.

Das três fichas distribuídas para preenchimento, no início do projeto, resultou uma única ficha, na sua maioria com respostas diretas, onde se pretende que o professor ajuste as atividades realizadas na UC aos objetivos e competências a atingir pelos estudantes, estimular o seu trabalho autónomo e a sua avaliação contínua.

No processo de consolidação das novas formações, as anteriores práticas docentes de organização e gestão curricular vão sendo reestruturadas e vão sendo introduzidas novas práticas pedagógicas, mais adaptadas às mudanças perspectivadas - não sendo um processo fácil, uma vez que a identidade do docente do Ensino Superior, pela sua autonomia e estratégias de sobrevivência, muitas vezes apresenta elevada relutância em colocar os seus próprios métodos de ensino em questão.

A valorização e implementação do trabalho autónomo do aluno, controlado pelo docente numa perspetiva de acompanhamento, integrado nas 
práticas de formação e avaliação, é um dos processos mais difíceis de implementar e avaliar, pelo que são necessárias estratégias que auxiliem este processo e promovam, por parte do docente, uma reflexão concertada da sua estratégia formativa, assim como, por parte do aluno, uma sensibilização para a importância da dedicação a este tipo de atividade autónoma. Com este objetivo e na perspetiva de facilitar o processo ao docente, numa lógica inovadora de formação surgem as fichas a preencher no âmbito do projeto ConstAp.

Para além da redefinição de novas fichas a implementar neste novo ano letivo, outras atitudes foram imperiosas e resultaram da inércia que por vezes ocorre em relação à mudança e à estruturação burocratizada de um sistema de ensino que, por via das circunstâncias, se foi acomodando a métodos novamente mais expositivos, contrariando aquilo que é preconizado por Bolonha para o Ensino Superior Politécnico, que aviva o paradigma do 'aprender fazendo'. Assim, impôs-se a execução de sessões em que se apresentaram os resultados do $1^{\circ}$ ano de implementação do projeto a toda a comunidade escolar de docentes e estudantes, para que o mesmo fosse contextualizado e sentido como um instrumento de apoio e ajuda à mudança de paradigma. Foi também explicitada a componente operacional do projeto em cada uma das Escolas/Unidades Orgânicas (UO) do IPCB, dando lugar a esclarecimentos e a momentos de discussão de novas metodologias e sugestões para a melhor prossecução do projeto.

Foi, pois, estimulada e incentivada a participação de mais UC's no Projeto, nos cursos onde tinha sido implementado anteriormente e/ou noutros cursos da UO. Neste sentido, foi introduzido um conjunto de alterações, que se identificam em seguida: simplificação das fichas; respostas direcionadas através das metodologias propostas; recolha de dados mais objetivos e mensuráveis.

Foi implementada, no atual ano letivo, uma versão revista do projeto, do qual se encontra atualmente em curso o processo de recolha de informação, para poder ser analisada.

Outro aspeto que se tornou fulcral foi um maior acompanhamento da implementação do projeto de cada UO, pelo que, para além do coordenador de curso, o responsável do grupo adstrito a cada UO ficou a dar o apoio necessário, assim como a efetuar a análise final dos dados do projeto. 


\subsection{As novas fichas}

Numa primeira fase, é importante decidir o objetivo principal da ficha para a qual a informação será utilizada. Posteriormente, em função da amplitude que se pretender atribuir à divulgação dos resultados, pode perspetivar-se a avaliação dos dados e uma reflexão sobre os mesmos, definindo pontos fortes e fracos do sistema de ensino.

As fichas informativas encontram-se organizadas em duas folhas diferentes. A ficha que consta do Anexo I pretende avaliar, por UC, as atividades de contacto e de trabalho autónomo desenvolvidas. O docente terá, agora, apenas que preencher dois campos principais. Por um lado, envolve o registo do que acontece em sala de aula, em horas de contato, através do preenchimento simplificado da informação sobre as atividades desenvolvidas, conduzidas pelo docente ou cumpridas pelo estudante, bem como a percentagem de tempo que ocuparam as várias atividades; por outro, pretende-se o registo, também simplificado, das atividades desenvolvidas em tempo de trabalho autónomo pelo estudante.

A segunda ficha, que se mantém, pretende apenas reunir informação sobre o tempo dedicado pelo estudante à realização de atividades em tempo de estudo autónomo, no sentido de articular o tempo autónomo previsto com o tempo de trabalho autónomo efetivo.

\subsection{Orientações para a futura implementação do Projeto}

Face aos conhecimentos que a literatura vai debitando sobre processos de mudança sociocultural que a sociedade vai registando, e em função da aprendizagem que a aplicação do projeto vai produzindo, é importante refletir sobre os aspetos positivos que se descortinaram, no sentido de os reforçar, e sobre os aspetos negativos que naturalmente afloram, para que se possam corrigir e ultrapassar.

A existência de um processo de monitorização anual parece corresponder a um período suficientemente sustentado para implementar um processo de melhoria permanente no projeto, até ao ponto em que as práticas assumidas o tornem dispensável.

Neste sentido, para além das questões operacionais e dos processos de resistência à mudança já referidos, existem algumas trajetórias que se podem ponderar: 
- Team matching;

- Validar e avaliar (efetivamente) as competências (e não os conteúdos);

- Reforçar a aposta na formação de docentes;

- Analisar as atividades avaliadas e construir um portefólio de boas práticas, retroalimentando a instituição;

- Fomentar o trabalho colaborativo e desenvolver um modelo de avaliação desse trabalho;

- Desenvolver os aspetos motivacionais junto de docentes e estudantes;

- Correlacionar a implementação do projeto com o sucesso académico e o abandono escolar;

- Desenvolvimento dos processos de comunicação professorestudante.

\section{Conclusões}

As mudanças implementadas pelo Processo de Bolonha, ainda que concluídas ao nível da organização dos planos curriculares, ainda estão por concretizar no âmbito das atividades pedagógicas desenvolvidas nas IES. Mesmo reconhecendo o esforço de muitos docentes em adequar as suas metodologias às novas exigências do processo de ensino-aprendizagem, ainda é necessário reproduzir as boas práticas pedagógicas e generalizar a utilização de metodologias ativas.

O projeto ConstAp vai ao encontro do preconizado pelos objetivos da Declaração de Bolonha e das exigências do processo de avaliação dos cursos no sentido da sua acreditação junto da Agência responsável, procurando conciliar esta componente normativa/regulamentar com as necessidades efetivas que os estudantes, altamente qualificados, sentem na atual sociedade - necessidades profissionais em rápida mudança que, mais do que conhecimentos, procuram competências. $\mathrm{O}$ alcance do projeto assenta, para além dos objetivos referidos ao longo deste trabalho e atendendo à metodologia definida, na aposta na mudança das práticas prosseguidas por uma significativa parte dos docentes da instituição, na mudança cultural nas 
práticas de transmissão de conhecimento e de avaliação. Para tal, julgamos que tanto a metodologia de intervenção quanto a organização de toda a implementação permitem reunir informação suficientemente sustentada que conduza à reflexão para a necessidade de mudança.

A implementação do Projeto ConstAp teve um contributo importante ao abordar as questões pedagógicas e promover o diálogo entre docentes sobre 'o que' e 'como' mudar. O projeto permite que os professores identifiquem claramente qual a relação entre os diversos elementos envolvidos no processo pedagógico: objetivos, competências, metodologias, atividades pedagógicas, atividades de trabalho autónomo e atividades de avaliação.

As atividades desenvolvidas têm permitido identificar as dificuldades no processo de mudança em curso e têm permitido orientar o trabalho desenvolvido no sentido de motivar e formar os docentes para enfrentar este desafio. Uma das apostas para o futuro passa por tornar mais abrangente a capacidade de intervenção dos docentes: por um lado, extrapolando para a comunidade científica a metodologia utilizada e os resultados atingidos, pela participação em congressos/seminários e/ou publicação de artigos em revistas internacionais; por outro, patrocinando a realização de ações de formação, apontando desde logo para as seguintes temáticas: no caso dos docentes, métodos de avaliação, preparação de material pedagógico e estatísticas no ensino; no caso dos estudantes, um seminário com a intervenção de técnicos que elucidem sobre as caraterísticas psicológicas dos estudantes que ingressam no Ensino Superior, com o objetivo principal de motivar a adesão ao Regime de Tutorias.

Outro dos aspetos salientes do projeto tem a ver com a necessidade de aprendermos com outros. Existem várias práticas institucionais difundidas, relatadas em fóruns científicos, em torno de metodologias de aprendizagem baseadas no modelo Problem Based Learning. É intenção da equipa construir, no âmbito do projeto, uma abordagem semelhante em cursos ministrados no IPCB por se entender que, não sendo generalizável, existem possibilidades de gerar bons resultados junto dos estudantes.

Parece-nos ser este um projeto transdisciplinar e cuja replicação e adaptação pode ser efetuada, sem grandes dificuldades, a variados contextos de formação superior. Em termos de visibilidade, a construção de uma página web permitirá um acesso externo mais facilitado à informação, bem como 
poderá passar a ser referenciado e acompanhado pelas IES, constituindo assim uma boa prática difundida para além da instituição.

\section{Referências}

Ardizzone, P., \& Rivoltella, P. (2004). Didáctica para e-learning. Métodos e instrumentos para la innovación de la enseñanza universitaria. Málaga: Ediciones Aljibe.

Attard, A., Di lorio, E., Geven, K., \& Santa, R. (2010). Student-centred learning - Toolkit for students, staff and Higher Education institutions. Brussels: T4SCL Project Steering Group. Retirado de http://www.esib.org/documents/publications/ SCL_toolkit_ESU_EI.pdf

Belisário, A. (2003). O material didático na educação à distância e a constituição de propostas interativas. In M. Silva, Educação online (pp. 135-146). São Paulo: Edições Loyola.

Biggs, J., \& Tang, C. (2007). Teaching for quality learning at university - What the student does ( $3^{\mathrm{a}}$ ed.). England: McGraw Hill Education/Open University Press.

Blikstrein, P., \& Zuffo, M. (2003). As sereias do ensino electrónico. In M. Silva, Educação online (pp. 23-38). São Paulo: Edições Loyola.

Bustamante, E. (2001). Era digital: Por un nuevo concepto de servicio público en la cultura y la educación. In M. Area, Educar en la Sociedad de la Información (pp. 27-36). Bilbao: Desclée.

Cachapuz, A. (2001). Em defesa do aperfeiçoamento pedagógico dos docentes do Ensino Superior. In C. Reimão, A formação pedagógica dos professores do Ensino Superior (pp. 55-61). Lisboa: Edições Colibri.

Esteves, M. (2010). Sentidos da inovação pedagógica no Ensino Superior. In C. Leite, Sentidos da pedagogia no Ensino Superior (pp. 45-61). Porto: CIIE/Livpsic.

European Comission (2009). ECTS user's guide, Luxembourg: Office for official publications of the European Communities. Luxembourg: Office for official publications of the European Communities.

Fry, H., Ketteridge, S., \& Marshall, S. (2009). A handbook for teaching and learning in Higher Education - Enhancing academic practice ( $3^{\mathrm{a}}$ ed.). New York: Routledge - Taylor \& Francis Group.

García-Valcárcel, A. (2001). La función docente del profesor universitario, su formación y desarrollo profesional. In A. García-Valcárcel, Didáctica universitaria (pp. 943). Madrid: Editorial La Muralla.

Gonçalves, F. R. (2006). A relação entre investigação, inovação e formação: Seus contributos para o desenvolvimento profissional do professor no quadro de Bolonha. In A. Tomé, Champs sociologiques et éducatifs - Enjeux aux-delà dês frontieres. Paris: L'Hamarttan.

Houghton, W. (2004). Engineering subject centre guide: Learning and teaching theory for engineering academics. Higher Education Academy - Engineering Subject Centre. 
Kennedy, D., Hyland, A., \& Ryan, N. (2007). Writing and using learning outcomes: A practical guide. Bologna Handbook C 3.4-1. Retirado de http://sss.dcu.ie/afi/docs/bologna/writing_and_using_learning_outcomes.pdf

Lagarto, J., \& Andrade, A. (2009). Sistemas de gestão de aprendizagem em e-learning. In G. Miranda, Ensino online e aprendizagem multimédia (pp. 56-80). Lisboa: Relógio D’Água.

Leite, C., \& Ramos, K. (2010). Questões da formação pedagógico-didática na sua relação com a profissionalidade docente universitária: Alguns pontos para debate. In C. Leite, Sentidos da pedagogia no Ensino Superior (pp. 29-43). Porto: CllE/Livpsic.

Ramos, F., Costa, N., Tavares, J. \& Huet, I. (2006). A staff development program for promoting change in Higher Education teaching and learning practices. In D. Kumar \& J. Turner, Education for the 21st century - Impact of ICT and digital resources, International Federation for Information Processing, vol. 210 (pp. 405-409). Boston: Springer.

Ritzen, J. (2010). A chance for European universities, or: Avoiding the looming university crisis in Europe. Amsterdam: Amsterdam University Press.

Román, J. (1980). Introducción a los métodos activos de ensenanza. In J. Román, G. Musitu \& E. Pastor, Métodos activos para Enseñanzas Medias y Universitarias (pp. 14-31). Madrid: Cincel-Kapelusz.

Santa, R., \& Geven, K. (2010). Student-centered learning - A survey on the views of national unions of students and Higher Education staff. Bucharest: T4SCLProject Steering Group. Retirado de http://www.esib.org/documents/ publications/Survey_Analysis_T4SCL.pdf

Veloso, H., Costa, A., \& Lopes, J. (2010). Factores, representações e práticas institucionais de promoção do sucesso escolar no Ensino Superior. Porto: U. Porto Editorial.

Vieira, F., Mamede, A., \& Lima, C. (2008). Staging pedagogy for autonomy: Two plays. In M. Jiménez Raya \& T. Lamb, Pedagogy for autonomy in language education in Europe: Theory, practice and teacher education (pp. 106-125). Dublin: Authentik.

Zabalza, M. (2003). Competencias docentes del profesorado universitario: Calidad y desarrollo profesional. Madrid: Narcea. 


\title{
IMPLEMENTING NEW PEDAGOGICAL PRACTICES IN HIGHER EDUCATION
}

\begin{abstract}
The implementation of new paradigms in Higher Education resulting from the introduction of the Bologna Process delivers an opportunity for the renewal. The Higher Education's quality involves the revision of curricula, the reorganization of teaching and learning by structuring courses, the qualification and training of teachers, the academic success and educational attainment, standards of performance, students' skills and institutions assessment and social confidence in the education provided. In 2010, it was outlined the project "Construction of Learning" (ConstAp) at the Polytechnic Institute of Castelo Branco, with the main objective of motivating the adoption of changes, particularly in terms of the methodologies and the systematic implementation of autonomous work, to ensure student's workload continuous throughout the semester. Quality improvement in Higher Education is the core issue which is intended to ensure by the project. This article examines the development of the project implemented at the IPCB in the scope of the Bologna Process.
\end{abstract}

Keywords

ConstAp; ECTS; Teaching-learning; Autonomous work

\section{IMPLEMENTACIÓN DE NUEVAS PRÁCTICAS PEDAGÓGICAS EN LA EDUCACIÓN SUPERIOR}

\section{Resumen}

La implementación de paradigmas en la Educación Superior desde la introducción del Proceso de Bolonia abre las puertas para la renovación. La calidad exige la revisión de los programas, la reorganización de la enseñanza/aprendizaje, mediante la restructuración de asignaturas y 
carreras, la cualificación/formación de los profesores, el éxito y los resultados escolar, la evaluación de las habilidades adquiridas y la confianza social en la Éducación Superior. En 2010 se inició el proyecto "Construcción de la Aprendizaje" (ConstAp) con el objetivo principal de motivar a los cambios, especialmente en cuanto a las metodologías adoptadas y la implementación del trabajo autónomo, para garantizar la carga de trabajo de un estudiante a lo largo del semestre. En este artículo se examina la aplicación del proyecto implementado en el IPCB bajo el Proceso de Bolonia, la contextualización de sus objetivos y las limitaciones de implementación.

Palabras clave

ConstAp; ECTS, Enseñanza-aprendizaje; Trabajo autónomo

Recebido em Julho/2012

Aceite para publicação em Março/2013 
Anexo I - Ficha aplicada por Unidade Curricular no Projeto ConstAp

o

Instituto Politécnic

CURSO DE LICENCIATURA EM ...

Atividades de contacto e trabalho autónomo

Unidade Curricular de

Data:

1. Atividades realizadas em sala de aula (Horas de contacto)

Aula n. ${ }^{0}$ :

Semana de realização da atividade:

\begin{tabular}{|l|l|l|l|l|l|l|l|l|l|l|l|l|l|l|}
\hline 1 & 2 & 3 & 4 & 5 & 6 & 7 & 8 & 9 & 10 & 11 & 12 & 13 & 14 & 15 \\
\hline & & & & & & & & & & & & & & \\
\hline
\end{tabular}

Tipo de Aula a realizar:

Teórica Teórico-Prática Prática e Laboratorial Trabalho de Campo

Estágio Orientação Tutorial Seminário Outra

Atividades a desenvolver nesta aula:

Pelo docente

1. Exposição de conteúdos

2. Realização de exercícios

$\%$ tempo:

3. Realização de ensaios

4. Visita Estudo/saída de campo

5. Demonstração de técnica/equipamento

6. Participação em simpósio/palestra/workshop

7. $\%$ tempo:

7. Outra

$\%$ tempo:

$\%$ tempo:

$\%$ tempo:

$\%$ tempo:

$\%$ tempo: 
Pelo estudante

2. Realização de ensaios

3. Atividades de leitura

4. Discussão/debate

5. Trabalho/pesquisa

6. Apresentação oral

7. Visita Estudo/saída de campo

8. Execução de técnica

9. Participação em
simpósio/palestra/workshop

10. Prova oral de avaliação

11. Apresentação oral

12. Prova escrita de avaliação

13. Apresentação / Discussão de relatórios para avaliação

14. Outra:
$\%$ tempo:

$\%$ tempo:

$\%$ tempo:

$\%$ tempo:

$\%$ tempo:

$\%$ tempo:

$\%$ tempo:

$\%$ tempo:

$\%$ tempo:

$\%$ tempo:

$\%$ tempo:

$\%$ tempo:

$\%$ tempo:

$\%$ tempo:

Total:

$100 \%$

Da(s) atividade(s) realizada(s) quais ponderam para a avaliação da UC? (realização de relatório, exercícios práticos, discussão em sala de aula, teste, trabalho, etc.) - se aplicável: 


\section{Atividades realizadas durante o Tempo de Trabalho Autónomo}

Assinalar a(s) semana(s) em que a atividade decorre:

\begin{tabular}{|l|l|l|l|l|l|l|l|l|l|l|l|l|l|l|}
\hline 1 & 2 & 3 & 4 & 5 & 6 & 7 & 8 & 9 & 10 & 11 & 12 & 13 & 14 & 15 \\
\hline & & & & & & & & & & & & & & \\
\hline
\end{tabular}

A cada atividade realizada em sala de aula (horas de contacto), podem estar associadas as respetivas horas de trabalho autónomo (realizadas pelos estudantes fora do período de contacto com o docente).

\section{Descrição da atividade:}

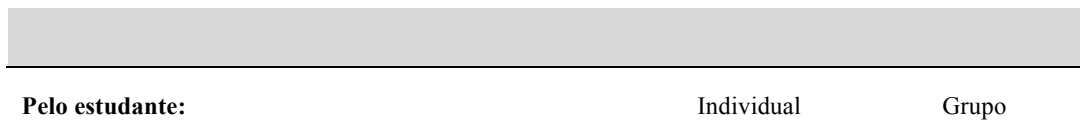

1. Realização de exercícios

2. Realização de ensaios

3. Atividades de leitura

4. Trabalho/pesquisa

5. Realização de trabalho

6. Preparação de apresentação oral

7. Visita Estudo/saída de campo

8. Execução de técnica

9. Participação em simpósio/palestra/workshop

10. Preparação para avaliação (estudar para prova escrita)

11. Outra

Observações: 